\title{
Printed Electrochemical Instruments for Biosensors
}

\author{
Valerio Beni, D. Nilsson, P. Arven, P. Norberg, G. Gustafsson and Anthony Turner
}

\section{Linköping University Post Print}

\section{Tweet}

N.B.: When citing this work, cite the original article.

Original Publication:

Valerio Beni, D. Nilsson, P. Arven, P. Norberg, G. Gustafsson and Anthony Turner, Printed Electrochemical Instruments for Biosensors, 2015, ECS Journal of Solid State Science and Technology, (4), 10, S3001-S3005.

http://dx.doi.org/10.1149/2.0011510jss

Copyright: Electrochemical Society http://www.electrochem.org/

Postprint available at: Linköping University Electronic Press

http://urn.kb.se/resolve?urn=urn:nbn:se:liu:diva-120887 
JSS Focus Issue on Micro-Nano Systems in Health Care and Environmental Monitoring

\title{
Printed Electrochemical Instruments for Biosensors
}

\author{
V. Beni, ${ }^{\text {a }}$ D. Nilsson, ${ }^{\mathrm{b}}$ P. Arven, ${ }^{\mathrm{c}}$ P. Norberg, ${ }^{\mathrm{b}}$ G. Gustafsson, ${ }^{\mathrm{b}}$ and A. P. F. Turner ${ }^{\mathrm{a}, *, \mathrm{z}}$ \\ ${ }^{a}$ Biosensors \& Bioelectronics Centre, IFM, Linköping University, Linköping SE-58183, Sweden \\ ${ }^{b}$ Acreo Swedish ICT AB, SE-601 17 Norrköping, Sweden \\ ${ }^{c}$ Electrical Engineering J2 Holding AB, SE-595 33 Mjölby, Sweden
}

\begin{abstract}
Mobile diagnostics for healthcare, food safety and environmental monitoring, demand a new generation of inexpensive sensing systems suitable for production in high volume. Herein we report on the development of a new disposable electrochemical instrument exploiting the latest advances in printed electronics and printed biosensors. The current system is manufactured under ambient conditions with all interconnections printed; electrochemical measurements and data elaboration are realized by the integration onto the platform of two chips: a MICROCHIP-PIC24F16KA101 and a Texas Instrument's LMP91000. A PEDOT.PSS vertical electrochromic display (VECD) is also incorporated into the system to visualize the data. A printed Enfucell $3 \mathrm{~V}$ manganese dioxide battery was used to deliver the required power. Finally, in order to demonstrate the utility of the system, screen-printed sensors for the detection of glucose were added and the performance of the overall system was evaluated.

(C) The Author(s) 2015. Published by ECS. This is an open access article distributed under the terms of the Creative Commons Attribution Non-Commercial No Derivatives 4.0 License (CC BY-NC-ND, http://creativecommons.org/licenses/by-nc-nd/4.0/), which permits non-commercial reuse, distribution, and reproduction in any medium, provided the original work is not changed in any way and is properly cited. For permission for commercial reuse, please email: oa@ electrochem.org. [DOI: 10.1149/2.0011510jss] All rights reserved.
\end{abstract}

Manuscript received May 27, 2015. Published July 10, 2015. This paper is part of the JSS Focus Issue on Micro-Nano Systems in Health Care and Environmental Monitoring.

Biosensors have achieved considerable success in both the commercial and academic arenas and the need for new, easy-to-use, home and decentralized diagnostics is now greater than ever. ${ }^{1}$ Healthcare spending is growing unsustainably and has already reached $18 \%$ of GDP in the USA and $9.5 \%$ of GDP in Europe. ${ }^{2}$ New thinking is crucial to finding effective solutions that deliver the high quality of life rightly demanded by our ever ageing population, while leveraging technology to deliver this in a cost-effective manner. Several key drivers are coming together to form a "perfect storm" that may just finally catalyze change to our 2,500 year-old model of healthcare delivery. Personalized medicine recognizes that every individual is different and needs a tailor-made health package; these differences can only be identified with an appropriate suite of diagnostics. ${ }^{3}$ Individuals are increasingly recognizing that data about their bodies should be owned by them and that they should have the choice to use and supplement this information. This generates consumer choice and drives evidence-based payment, where regimens and treatments are paid for on the basis of successful outcomes. Decentralization will be the key to modern health and care; in order to achieve this, the development of novel diagnostics is needed. ${ }^{1}$ Merging paper diagnostics and printed electronics in the form of fully-integrated platforms such as this all-printed biosensing system, together with integrated sampling and wearable, disposable and/or interactive devices, could be an ideal technological answer to this need.

Dipstick tests and lateral-flow devices are the most established formats for "paper" based assays ${ }^{4}$ with arguably the most emblematic and successful of these being the dipstick test for glucose in urine ${ }^{5}$ and the human pregnancy test. ${ }^{6}$ The basic configuration of these tests consists of a supported paper/membrane, with nitrocellulose as the most popular material, on which different functional zones are defined including a: sample loading region; filtering/separation zone; and test zone. Paper microfluidics can be considered to have been originated by Müller and Clegg ${ }^{7}$ who demonstrated the preferential elution of a mixture of pigments within a channel created by impregnating a paraffin barrier on paper. The confined channel sped up the sample diffusion process and reduced sample consumption. Printed liquidic circuits, comprising wax patterns on one or more layers of filter paper or membrane to create impermeable barriers, was claimed by Chandler in $1996 .{ }^{8}$ However, in the last decade or so, several authors have explored the

${ }^{*}$ Electrochemical Society Active Member.

${ }^{\mathrm{z} E}$-mail: anthony.turner@liu.se use of paper for the development of complex microfluidic platforms for performing significantly more complex assays. ${ }^{9,10}$ Vella et al. ${ }^{11}$ developed a 3D paper based microfluidic assay for the simultaneous colorimetric detection of liver function parameters (alkaline phosphatase, ALP, and aspartate aminotransferase, AST and total protein). Hossain et al. ${ }^{12}$ developed a solid-phase, bioactive lab-on-paper sensor incorporating the enzyme ( $\beta$-galactosidase) for mediated colorimetric detection of heavy metals $(\mathrm{Hg}(\mathrm{II}) ; \mathrm{Ag}(\mathrm{I}), \mathrm{Cu}(\mathrm{II})$; $\mathrm{Cd}(\mathrm{II})$; $\mathrm{Pb}(\mathrm{II})$; $\mathrm{Cr}(\mathrm{VI})$; Ni(II)). Despite the fact that paper-based assays have been shown to have great potential for low-cost and decentralized analysis (minimum sample preparation and high portability) the continuous demand for better sensitivity has posed a significant challenge to conventional colorimetric detection. This challenge has prompted the idea of coupling paper-based fluidics with instrumental detection techniques toward the development of quantitative and sensitive assays. Several sensing mechanisms, such as colorimetric detection, fluorescence, chemiluminescence and electrochemistry have been proposed. ${ }^{4}$ Various authors have suggested the use of mobile phones as detectors for optical assays; however, hardware (camera and illumination) and software (compatibility with existing platforms and continuously evolving product lines) limitations still need to be overcome to make this technological approach commercially valuable. ${ }^{4}$ Among the different sensing approaches, electrochemistry has the advantage of not being affected by factors such as ambient light and illumination, and to be highly compatible with paper-based fluidics, since electrodes can easily be fabricated by the printing technologies (e.g. screen printing, flexography and ink-jet technology) that are extensively used in the fabrication of paper-based fluidics. ${ }^{1,13-15}$

Dughchai et al. ${ }^{16}$ developed an electrochemical paper-based amperometric biosensor array for the simultaneous detection of uric acid, glucose and lactate. Nie et al. ${ }^{17}$ developed electrochemical MicroPaper-based Analytical Devices (E $\mu$ PADs) for the detection of several human health parameters (e.g., glucose, cholesterol, lactate and alcohol) in blood or urine. The most important feature of the proposed system was the fact that this could be interfaced with a commercial reading device (True Track blood glucometer; CVS/Pharmacy). Liu et al. ${ }^{18}$ reported on the development of a coated and laminated batterypowered, micro-electrochemical sensing platform on paper for the detection of glucose and hydrogen peroxide. The proposed platform was able to report its output using an electrochromic display. These last two reports tried to tackle one of the most relevant limitation of current sensing platforms, i.e. the need for an external reader. ${ }^{4,13}$ 
Printed electronics (PE) or hybrid printed electronics (Hy-PE), where printed elements and, where necessary, silicon-based components are combined in a single device, are expected to play a significant role in the development of fully-integrated multi-functional systems. ${ }^{19}$ In the last decade, the use of PE has been demonstrated for the fabrication of different devices, such as batteries, ${ }^{20}$ thin film organic transistors, ${ }^{21}$ flexible displays, ${ }^{22}$ solar cells ${ }^{23}$ and cell-based biosensors. ${ }^{24}$ Printed biosensors have already had enormous commercial success, especially in the area of home blood glucose monitoring for people with diabetes ${ }^{25}$ and there is considerable appeal in realizing complete printed instruments using the same, low-cost approach. Despite the fact that several authors demonstrated the fabrication of individual electronic components, the exclusive use of PE for the fabrication of fully integrated systems independent from any external input and silicon-based technology is still far from becoming reality. As an intermediate step, the use of Hy-PE has gained popularity in the development of increasingly more complex systems. Yang et al. ${ }^{26}$ developed a stand-alone wearable bio-patch, based on the integration of CMOS technology and on-paper inkjet printing, for monitoring biosignals from patients. The system integrated ink jetprinted electrodes, a soft battery, printed interconnections, a CMOS processor/microcontroller and printed antenna for data transmission. Siegel et al. ${ }^{27}$ demonstrated the possibility of producing a hybrid, printed and foldable circuit board on paper via the combination of metal track deposition (via, evaporation, sputtering and airbrushing) together with the integration of CMOS components, an LED and a battery. More recently, Eshkeiti et al. ${ }^{28}$ demonstrated the fabrication of a screen-printed, multilayer hybrid printed board, which was compatible with different flexible substrates. The proposed circuit board demonstrated the possibility of combining screen-printing and hybrid CMOS technology for the fabrication of active flexible electronic devices; nevertheless the proposed system still required an external power supply and display.

Herein, we describe the first fully integrated, hybrid printed instrument for amperometric biosensing and demonstrate this for the measurement of glucose. The proposed approach combines the sophistication of advanced electrochemical biosensors with a simple manufacturing technique to create an on-plastic (or on-paper) useand-throw instrument. The system is manufactured under ambient conditions. All interconnections are printed and anisotropic conductive glue is used for the interconnection between the printed conductors and the CMOS-based chips (potentiostat and microcontroller), and power source. A screen-printed manganese dioxide battery and a vertical electrochromic display, working in reflective mode, are incorporated in the instrument.

This integrated biosensing platform forms a workhorse in our hands for a variety of diagnostic systems including enzyme electrodes, electrochemical sensors for enzymes, label-free affinity sensors, aptasensors, DNA sensors and robust devices based on imprinted and smart polymers. Using these technologies, we envision over-thecounter paper instruments for self-diagnosis of common diseases, home kits to support people after transplant surgery or cancer treatment, smart cartons for pharmaceuticals, pocket tests for allergens, food toxicity, drinking water etc., and wearable strips or patches that communicate with mobile telecommunications. Realization of these paradigm-changing new products requires the effective harnessing of emerging technology, inspired vision from clinical partners or others "users" and leading-edge engineering to design and produce functional systems in appropriate volumes at the right cost.

\section{Materials and Methods}

The biosensor, display and circuit were fabricated by screenprinting onto a $125 \mu \mathrm{m}$ thick polyethylene terephthalate (PET) substrate (Polyfoil Bias). In order to minimize substrate deformation during the printing process, the PET substrate was first pretreated by heating at $130^{\circ} \mathrm{C}$ for $30 \mathrm{~min}$. The biosensor was based on a twoelectrode configuration with working $\left(0.018 \mathrm{~cm}^{2}\right.$ of geometrical area) and counter/reference electrodes printed in carbon using an ELEC-
TRODAG PF-407A (Acheson, Henkel Corporation, USA) ink. The display comprised a PEDOT electrochromic ink, followed by deposition of the electrolyte with a final carbon ink forming the digit elements and was fabricated accordingly to a previously established protocol. ${ }^{29-30}$ The low power display required a voltage $<3 \mathrm{~V}$ and indicated the sensor output on a 0 to 9.5 scale with a relatively low resolution of 0.5 . The conductive tracks were printed using an $\mathrm{Ag}$ (Ag5000, DuPont, U.K.) ink. Protection of the conductive tracks of the biosensor was achieved by the use of a dielectric layer (D2070423D5, Gwent Group, UK). A semi-automatic screen printer (SCF-550 screen printer, Eickmeyer GmbH, Germany) was used to fabricate the electrodes and other components. An anisotropic conductive glue was used to connect the CMOS components. Precise delivery of the glue was made possible by the use of a semi-automated dispenser. The screen-printed manganese dioxide battery with a nominal voltage of $3 \mathrm{~V}$, was supplied by Enfucell Oy (Finland), but in the final device it can be printed as part of the overall fabrication process.

Amperometric measurements were performed using a micropower analog potentiostat (LMP91000, Texas, Instruments, USA). This potentiostat chip is a programmable analog front-end system for use in micro-power electrochemical sensing applications. The LMP91000 is designed for 2- or 3- lead sensor applications. The chip is appropriate for amperometric sensing in solution or gases. Communication was achieved using a PIC24F16KA101 microcontroller. The PIC24F16KA101 (Microchip) is a 20-Pin General Purpose, 16Bit Flash Microcontroller with nanoWatt XLP Technology. It typically has low power consumption with run-mode currents down to $8 \mu \mathrm{A}$, idle mode currents down to $2 \mu \mathrm{A}$, deep sleep-mode currents down to $20 \mathrm{nA}$ and an operating voltage range of $1.8 \mathrm{~V}$ to $3.6 \mathrm{~V}$.

Potassium hexacyanoferrate, ferric chloride, potassium chloride, concentrated 36-38\% hydrochloric acid, glucose, Nafion, isopropanol, PBS tablets and $30 \%$ hydrogen peroxide were purchased from Sigma Aldrich (Sweden). Glucose oxidase from Aspergillus niger $(110 \mathrm{U} / \mathrm{mg}$ ) was purchased from Amresco (USA). All solutions were prepared with ultrapure (18.2 M $\Omega$ ) water from a Millipore Milli$\mathrm{Q}$ water purification system (Billerica, MA).

Hybrid printed circuit.- Figure 1 shows a schematic representation of the hybrid printed circuit. The main elements are printed circuitry and connections (to electrode and external PC for microcontroller programming), the actuators (push buttons), the communication (microcontroller) and potentiostat chips, the display and the battery. The printed circuit was fabricated by the alternate printing of
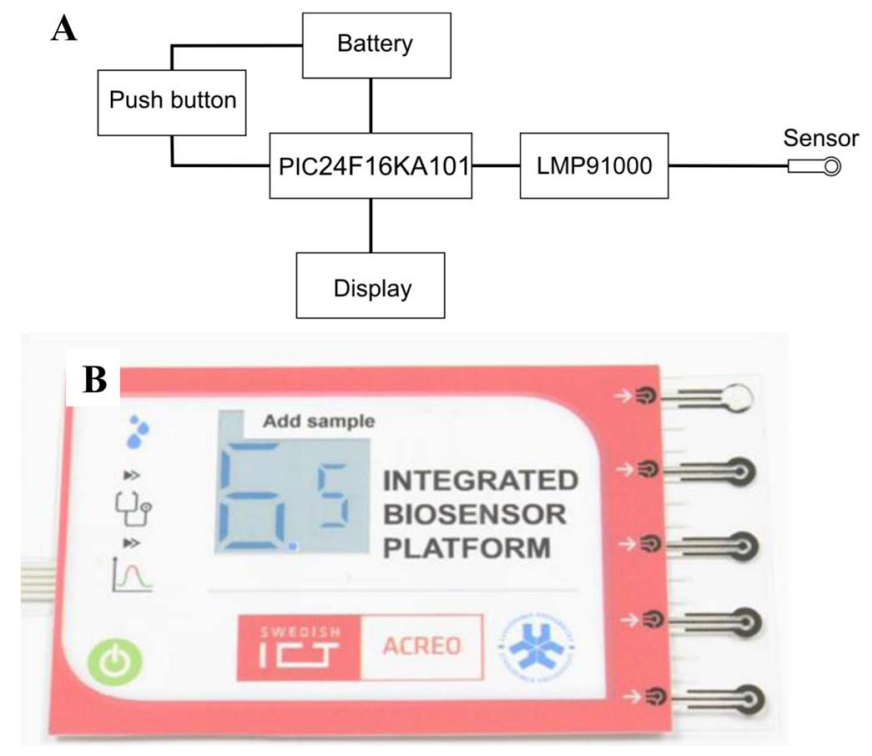

Figure 1. A) Schematic circuit of the integrated system. B) Photograph of the integrated instrument. 


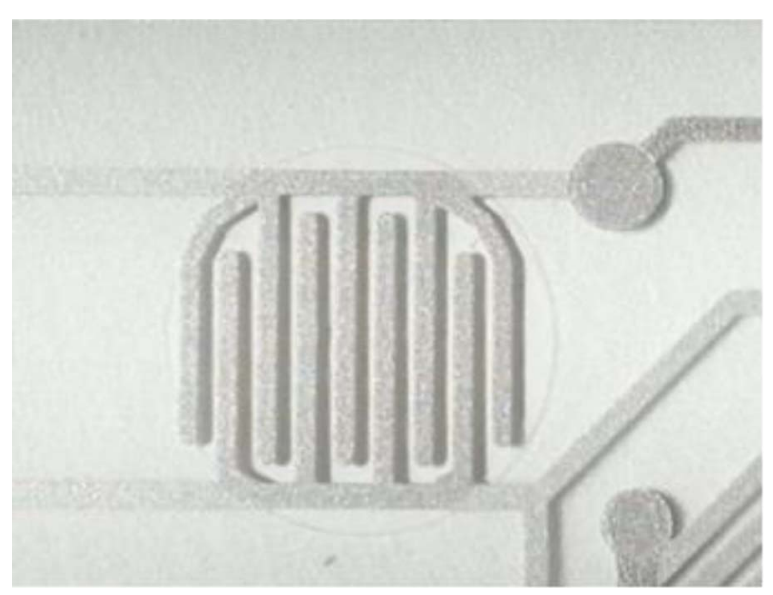

Figure 2. Photograph of the printed on/off switch button.

conductive elements/tracks and insulators. Conductive tracks (150 to $300 \mu \mathrm{m})$ and actuators were fabricated using the Ag based ink.

Figure 2 shows a detailed photograph of the printed on/off switch button. This was made of two components: printed interdigitated electrodes and a conductive element (incorporated in the lamination layer) that are mechanically short-circuited by pressing with the finger on the top element. The switch has two main functions: (i) conserving the charge of the battery; and (ii) initiating the measurement process by triggering the potentiostat, resulting in conserving battery power, and also initiating a timing sequence indicated by the display, which requests the introduction of the sample prior to the measurement by way of an icon.

CMOS components were packaged in their designated spots by the use of anisotropic conductive glue. Following mounting of the CMOS components, the battery were integrated with the printed hybrid circuit board by the use of anisotropic tape and conductive glue. The final step in the fabrication of the integrated hybrid system was lamination of the circuit to ensure its protection (Figure 1B).

Biosensor fabrication and characterization.- The biosensor chip was produced by screen printing. In order to achieve the desired design, four different masks were designed and fabricated (Mesh, 15034 Hibond). The first step of the fabrication consisted of printing the silver conducting tracks on the PET substrate. In order to avoid deformation of the PET substrate during the different curing steps, the PET substrate was pre-treated in oven at $130^{\circ} \mathrm{C}$ for $30 \mathrm{~min}$. Following the curing of the Ag tracks $\left(10 \mathrm{~min}\right.$. at $\left.80^{\circ} \mathrm{C}\right)$, the carbon working $(2 \mathrm{~mm}$ diameter disk) and counter/reference electrodes were printed (cured $15 \mathrm{~min}$. at $120^{\circ} \mathrm{C}$ in oven). Finally the insulation layer was deposited in order to protect the conductive tracks and to define the area of the working and of the reference/counter electrodes ( 3 sequential layers, UV cured).

The bare electrodes were then modified by a combination of chemical deposition of a Prussian blue catalyst and the deposition of an enzyme membrane. The Prussian blue was deposited following a previously optimized protocol. ${ }^{31}$ A mixture of $\mathrm{FeCl}_{3}(5 \mathrm{mM})$ and of $\left.\mathrm{K}_{3}\left[\mathrm{Fe}(\mathrm{CN})_{6}\right)\right](5 \mathrm{mM})$ in $\mathrm{HCl} 0.1 \mathrm{M}$ and $\mathrm{KCl} 0.1 \mathrm{M}$ was prepared fresh and left to react for 20 minutes in the dark. Following this, $2 \mu l$ of the solution was drop-cast onto the working electrode and left to react for further 15 minutes in the dark. Following this, $1 \mu \mathrm{l}$ of a $0.5 \mathrm{M}$ solution of $\mathrm{H}_{2} \mathrm{O}_{2}$ in $0.1 \mathrm{M} \mathrm{HCl}$ and $\mathrm{KCl} 0.1 \mathrm{M}$ were added and the new mixture was left to react for further 60 minutes in the dark. This was followed by copious rinsing with ultrapure water and drying with nitrogen. When not in use, the electrode elements were stored at $4{ }^{\circ} \mathrm{C}$ in the dark. The biorecogniton layer was prepared as follows: $1 \mu \mathrm{L}$ of a solution containing $1.5 \mathrm{mg} \mathrm{mL}^{-1}$ of glucose oxidase and $0.3 \%(\mathrm{v} / \mathrm{v})$ of Nafion in $15 \%$ water $+85 \%$ isopropanol was drop-cast onto the previously functionalized working electrode and left to dry at $4{ }^{\circ} \mathrm{C}$ overnight. Following rinsing with ultrapure water and drying with nitrogen, the electrode elements were stored at $4{ }^{\circ} \mathrm{C}$ in the dark. The developed sensors were tested using cyclic voltammetry and amperometric measurements. The latter tests were performed using two different setups: a commercial bench top potentiostat (IviumStat, Ivium, The Netherlands) and the potentiostat chip (LMP91000, Texas, Instruments) mounted onto a PCB-based system resembling the technical characteristics of the fully integrated system.

\section{Results and Discussion}

Prior to the packaging of the CMOS components, characterization of the circuit was performed, including testing the conductivity of the tracks and for possible short-circuiting between the different layers of the printed circuit. Integration of the CMOS component was performed by gluing them using an anisotropic glue. The final packaged potentiostat is presented in Figure 1B. Characterization of the different components of the system was performed either using the printed hybrid system or a PCBbased system.

Operational protocol.- Operational control of the fully integrated system was performed by custom-written, software using $\mathrm{C}$ as the programming language. The developed software allowed the autonomous analysis of a sample from sample delivery to the display of the result.

Sample analysis was performed according to the following protocol:

(i) Initiating the measurement procedure, via the mechanical switch-on button; this will trigger the micro-controller that will instruct the potentiostat to apply a pre-defined potential difference between the working and the counter/reference electrodes. During this period a waiting message will be displayed onto the screen

(ii) Start monitoring the current passing in the circuit (baseline); at this stage the system is ready to receive a sample. A message icon requesting sample delivery (in the form of a drop) will be displayed on the screen.

(iii) Any change in the base current will be interpreted by the system as an indication that the sample has been added onto the sensor.

(iv) Start a $10 \mathrm{~s}$ count down; following this time the current will be sampled and used, following baseline subtraction, as the analytical signal.

(v) Elaboration of the analytical signal by the micro-controller using an in-built calibration curve.

(vi) Approximation of the output and display of it in the display.

Biosensor characterization.- As described in the Materials and methods section, the biosensor was developed using a carbon, screenprinted, two-electrode system. The biosensor involved two reactions mechanisms: (i) the enzymatic oxidation of the D-Glucose by the immobilized glucose oxidase with consequent generation of hydrogen peroxide (Eq. 1); and (ii) the chemical reduction of hydrogen peroxide catalyzed by the chemically deposited Prussian blue (Eq. 2).

$$
\begin{gathered}
\text { D-Glucose }+\mathrm{H}_{2} \mathrm{O}+1 / 2 \mathrm{O}_{2} \rightarrow \text { Gluconic Acid }+\mathrm{H}_{2} \mathrm{O}_{2} \\
\mathrm{H}_{2} \mathrm{O}_{2}+2 \mathrm{Fe}^{\mathrm{II}}\left[\mathrm{Fe}^{\mathrm{II}}(\mathrm{CN})_{6}\right]^{2-}+2 \mathrm{H}^{+} \rightarrow 2 \mathrm{H}_{2} \mathrm{O}+2 \mathrm{Fe}^{\mathrm{III}}\left[\mathrm{Fe}^{\mathrm{II}}(\mathrm{CN})_{6}\right]^{-}
\end{gathered}
$$

Detection was then performed by the electrochemical reduction of the previously oxidized $\mathrm{Fe}$.

Prior to drop-casting the enzyme containing membrane, the presence of Prussian blue on the modified electrode was checked by cyclic voltammetry. Figure 3A shows a typical cyclic voltammogram recorded in $0.1 \mathrm{M} \mathrm{KCl}$

As can be seen from Figure 3A, two clear Faradic processes were recorded at the modified electrode indicating the successful functionalization of the electrode with Prussian blue. Following the deposition of the enzymatic membrane, amperometric measurements for different concentrations of D-glucose in buffer solution were recorded using 

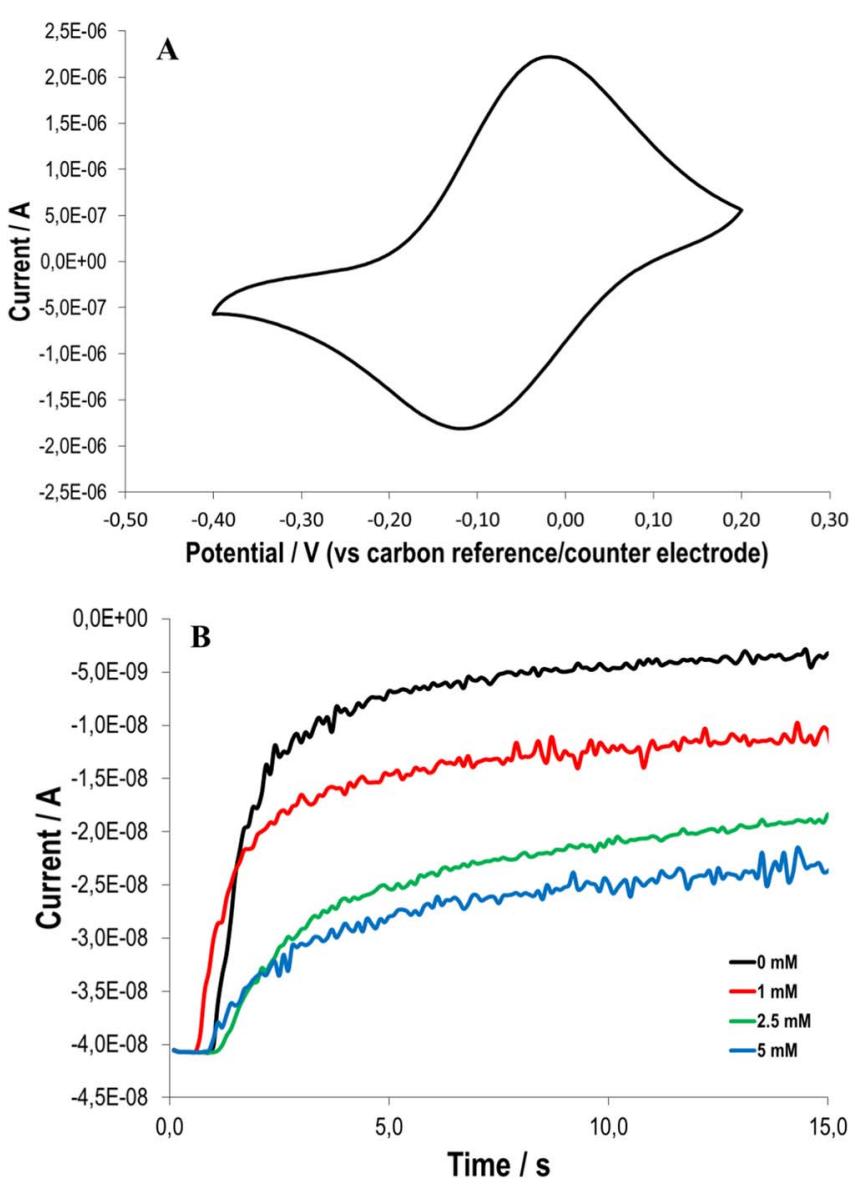

Figure 3. A) Cyclic voltammetry $\left(50 \mathrm{mVs}^{-1}\right.$ in $\left.\mathrm{KCl} 0.1 \mathrm{M}\right)$ of a Prussian blue modified electrochemical sensor; B) Amperometric measurements (applied potential $-400 \mathrm{mV}$ ) for different concentrations of glucose in $10 \mathrm{mM}$ PBS (pH 7.4).

a commercial potentiostat, in order to test the performance of the biosensor. Figure 3B shows a typical amperometric response from the biosensor in the absence and presence of D-glucose (1, 2.5 and $5 \mathrm{mM})$. As can be seen from this figure, an increase in the anodic current was recorded with increase in concentration of glucose. Furthermore, this set of experiments revealed a significant charging current following addition of the sample solution onto the biosensor surface; the recorded current tended to level off after few seconds. Subsequently it was decided to implement a $10 \mathrm{sec}$. delay between sample introduction and signal recording to eliminate this effect from the final measurement value.

Evaluation of the performance of the on-chip potentiostat and of the circuit design was performed by comparing the calibration curve obtained with a bench-top potentiostat (IviumStat) and those obtained with the LMP91000, Texas Instruments potentiostat mounted onto the PCB board circuit. During this set of experiments, electrodes from the same electrode sheet and functionalized in parallel were used. Detection was performed according to the following protocol: (i) a potential of $-400 \mathrm{mV}$ (vs the carbon reference/counter electrode) was applied to the working electrode; (ii) a drop of the sample was added onto the electrode; and (iii) the analytical signal was recorded after a delay of $10 \mathrm{sec}$.

Figure 4 presents calibration curves recorded with the two setups; clearly the two systems delivered comparable results, confirming the suitability of the proposed circuit design. Furthermore these experiments showed that the developed biosensor had a linear response between 0 and $5 \mathrm{mM}$ glucose; this result was expected since the Prussian blue catalyst works best at low concentrations of hydrogen peroxide, the bio-product of the enzymatic reaction used as the

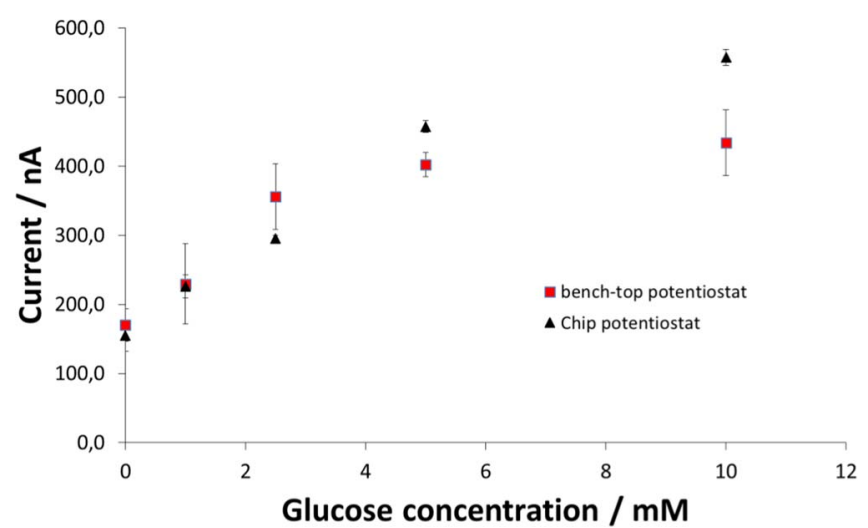

Figure 4. Comparison of the calibration curves obtained with the dummy (black symbols) and bench-top potentiostat (IviumStat, red symbols). Each point is the average of the response of 4 individual glucosensors.

redox active compound. ${ }^{32}$ This type of high sensitivity over a relatively low dynamic range is well suited to glucose sensing in interstitial fluid, which in turn is compatible with patch-type, wearable sensor. $^{33}$

The PCB system based on LMP91000 was used to calculate a calibration curve (between 0 and $5 \mathrm{mM}$ ) to be used for calibrating the integrated system in order to perform independent measurement without the need for any external element. The calibration curve was built by averaging the responses of 4 independent electrodes. The calibration curve obtained was then extrapolated to fit the 0 to 9.5 scale of the display and uploaded onto the microcontroller for post analysis response evaluation and display.

In order to demonstrate the suitability of the designed circuit and of the selected components for performing a model test (for glucose) the stability and accuracy of the system was assessed by performing consecutive measurements of two different analyte concentrations $(0$ and $5 \mathrm{mM}$ ) using the PCB-based circuit. No significant variation was observed at $0 \mathrm{mM}$, but some fluctuation of the response at $5 \mathrm{mM}$ was recorded. Five consecutive measurements led to an average reading of $4.9 \pm 0.5 \mathrm{mM}$; this small systematic error could be the result of a combination of factors including the chemical/photo degradation of the sensor (a consistent reduction in the absolute current response was observed) and/or to the algorithm used to round the data. To verify the reproducibility of the measurement protocol and the system, the performance of the printed instrument was compared to the PCBbased circuit, both powered using a similar external power source. This was performed by comparing the response obtained for 3 different concentrations: $0.1 ; 1$; and $5 \mathrm{mM}$ of the analyte. A summary of these results is presented in Table I.

Finally the reproducibility of the hybrid printed platform, powered by the integral printed battery was tested. This was done by performing several measurement using the same concentration of analyte $(5 \mathrm{mM})$. Once again, an average response of $4.9 \pm 1(\mathrm{mM})$ was recorded. The increase in the standard deviation could be due to additional instability of the system due to fluctuation in the power reaching the microcontroller from the battery that is expected to influence the applied bias potential (being defined as a percentage of the power reaching the system) between the working and the reference/counter

Table I. Comparison of analytical performances of the PCB-based circuit and the hybrid printed system.

\begin{tabular}{ccc}
$\begin{array}{c}\text { Nominal sample } \\
\text { concentration }\end{array}$ & $\begin{array}{c}\text { PCB system } \\
\text { Reading }\end{array}$ & $\begin{array}{c}\text { Hybrid printed system } \\
\text { Reading }\end{array}$ \\
\hline $0 \mathrm{mM}$ & 0 & 0 \\
$1 \mathrm{mM}$ & 1 & 1 \\
$5 \mathrm{mM}$ & $5 \pm 0.6$ & $4.7 \pm 0.3$
\end{tabular}


electrodes. This may be due to the temporary nature of the battery mounting (currently designed to allow reuse of the hybrid circuit), which would be overcome in the final integrated manufacturing process.

\section{Conclusions}

We have documented, for the first time, a fully integrated electrochemical instrument suitable for mass production using screen/web printing. This facilitates the manufacture of extremely inexpensive amperometric sensing instruments suitable for liquid (and potentially gaseous) analytes. We have demonstrated the feasibility of this method for printing a hybrid glucose sensing instrument on plastic (and potentially on paper) and shown that this is capable of reproducibly measuring physiologically relevant concentrations. In addition, we have preliminary results (not reported here) for the detection of other analytes such as lactate and $\beta$-hydroxybutryrate on this platform. Such an inexpensive, disposable device could provide an alternative to conventional meters and be used for a wide range of over-the-counter diagnostic applications. In addition to replacing regular meters with digital displays, we also have the ability to incorporate antennae for RFID or Bluetooth communication with a phone or tablet. Near-field communication is our preferred method for health applications, while Bluetooth may be well suited to environmental monitoring. Likewise, the printed configuration can be readily adapted to accept alternative power sources such as printed solar cells or fuels cells. Product concepts include use-and-throw biodegradable OTC meters, smart cartons where an analytical instrument is incorporated in a pharmaceutical or treatment package, and wearable telemetric plasters including sampling systems. Future development will result in further cost reduction, new applications and a wider diversity of formats, and possibly even print-on-demand analytical devices.

\section{Acknowledgments}

The authors gratefully acknowledge the support of their respective team members in the Biosensors and Bioelectronics Centre at Linköping University and at Acreo Swedish ICT. In particular, we thank Dr Raeann Gifford (now at Medtronic, USA), who played an essential role in catalyzing this project, David Westerberg for the packaging and the printing team in the Printed Electronics Arena: Anurak Sawatdee, Jessica Åhlin, Marie Nilsson and Lars-Olov Hennerdal. This paper is dedicated to the memory of Professor Marco Mascini (1940-2015), a friend and colleague who inspired all around him and did so much to advance the field of biosensors.

\section{References}

1. A. P. F. Turner, Chemical Society Reviews, 42(8), 3184 (2013).

2. http://data.worldbank.org/indicator/SH.XPD.TOTL.ZS

3. M. U. Ahmed, I. Saaem, P. C. Wu, and A. S. Brown, Critical Review in Biotechnology, 34(2), 180 (2014).

4. A. K. Yetisen, M. S. Akram, and C. R. Lowe, Lab on a Chip, 13, 2210 (2013).

5. A. H. Free, E. C. Adams, M. L. Kercher, H. M. Free, and M. H. Cook, Clinical Chemistry, 3, 163 (1957).

6. http://uk.clearblue.com/

7. R. H. Müller and D. L. Clegg, Analytical Chemistry, 21, 1123 (1949).

8. D. D. Liana, B. Raguse, J. J. Gooding, and E. Chow, Sensors, 12, 11505 (2012).

9. J. A. Chandler, Assay device and method, British Biocell International Ltd, EP 0808457, (1996).

10. W. K. T. Coltro, C.-M. Cheng, E. Carrilho, and D. Pereira de Jesus, Electrophoresis, 35, 2309 (2014)

11. S. J. Vella, P. Beattie, R. Cademartiri, A. Laromaine, A. W. Martinez, S. T. Phillips, K. A. Marica, and G. M. Whitesides, Analytical Chemistry, 84(6), 2883 (2012).

12. S. M. Hussain and J. D. Brennan, Analytical Chemistry, 83, 8772 (2011).

13. E. J. Maxwell, A. D. Mazzeo, and G. M. Whitesides, MRS Bulletin, 38, 309 (2013).

14. B. Liu, D. Du, X. Hua, X.-Y. Yu, and Y. Lin, Electroanalysis, 26, 1214 (2014).

15. A. S. G. Reddy, B. B. Narakathu, M. Z. Atashbar, M. Rebros, E. Hrehorova, and M. Joyce, IEEE Sensors 2010 Conference, 1596 (2010).

16. W. Dughchai, O. Chailapakul, and C. S. Henry, Analytical Chemistry, 81, 5821 (2009)

17. Z. Nie, C. A. Nijhuis, J. Gong, X. Chen, A. Kumachev, A. W. Martinez, M. Narovlyansky, and G. M. Whitesides, Lab on a Chip, 10, 3163 (2010).

18. H. Liu and R. M. Crooks, Analytical Chemistry, 84, 2528 (2012)

19. M. Berggren, D. Nilsson, and N. D. Robinson, Nature Materials, 6, 3 (2007).

20. A. M. Gaikwad, D. A. Steingart, T. N. Ng, D. E. Schwartt, and G. L. Whiting, Applied Physics Letters, 10(23), 233302 (2013).

21. B. Kang, W. H. Lee, and K. Cho, Applied Materials and Interfaces, 5, 2302 (2013).

22. J. Kawahara, P. A. Ersman, D. Nilsson, K. Katoh, Y. Nakata, M. Sandberg, M. Nilsson, G. Gustafsson, and M. Berggren, Journal of Polymer Science B-Polymer Physics, 51(4), 265 (2013).

23. Y. H. Zhou, F. L. Zhang, K. Tvingstedt, S. Barrau, F. H. Li, W. J. Tian, and O. Inganas, Applied Physics Letters, 92(23), 233308 (2008).

24. M. Zhang, P- Lin, M. Yang, and F. Yan, Biochimica et Biophysica Acta, 1830, 4402 (2013).

25. J. D. Newman and A. P. F. Turner, Biosensors and Bioelectronics, 20, 2435 (2005).

26. G. Yang, L. Xie, M. Mäntysalo, J. Chen, H. Tenhunen, and L.-R. Zheng, IEEE Transactions on Information Technology in Biomedicine, 16(6), 1043 (2012).

27. A. C. Siegel, S. T. Phillips, M. D. Dickey, N. Lu, Z. Suo, and C. M. Whitesides, Advance Functional Materials, 20, 28 (2010).

28. A. Eshkeiti, A. S. G. Reddy, S. Emamian, B. B. Narakathu, M. Joyce, M. Joyce, P. D. Fleming, B. J. Bazuin, and M. Z. Atashbar, IEEE Transactions on Components, Packaging and Manifacturing Technology, 5(3), 415 (2015).

29. P. Andersson, R. Forcheimer, P Teharani, and M. Berggren, Advanced Functional Materials, 17, 3074 (2007),

30. J. Kawahara, P. Andersson Ersman, D. Nilsson, K. Katoh, Y. Nakata, M. Sandberg, M. Nilsson, G. Gustafsson, and M. Berggren, Journal of polymer science, Part B: Polymer physics, 51, 265 (2013).

31. A. N. Sekretaryova, V. Beni, M. Eriksson, A. A. Karyakin, A. P. F. Turner, and M. Y. Vagin, Analytical Chemistry, 86(19), 9540 (2014)

32. A. A. Karyakin, Electroanalysis, 13(10), 813 (2001).

33. A. J. Bandodkar, W. Jia, C. X. Yardımc Wang, J. Ramirez, and J. Wang, Analytical Chemistry, 87(1), 394 (2015). 